\title{
Overall Framework Design of an Intelligent Dynamic Accounting Information Platform Based on the Internet of Things
}

\author{
http://dx.doi.org/10.3991/ijoe.v12i05.5728 \\ Feng Qiu \\ Chongqing College of Electronic Engineering, Chongqing, China
}

\begin{abstract}
The development of the Internet of things (IOT) is changing our lives by making the objects we used every day convenient and "intelligent." The application and development of IOT also have far-reaching effects on enterprise accounting information. A radio frequency technology accounting information platform is proposed by introducing the characteristics of IOT technology and accounting information. The overall design of the intelligent 3D dynamic accounting information platform includes data acquisition, cost accounting, and accounting document generation and report output. The subsystem design includes hardware and software designs. The 3D dynamic accounting information platform based on IOT technology implements accounting work and supervision, as well as promotes the development of accounting information work for enterprise management services.
\end{abstract}

Index Terms-dynamic accounting information platform; RFID technology; IOT

\section{INTRODUCTION}

Computer and network technologies, as representatives of the information wave, have swept the world and promoted the transformation of nearly all aspects of society. The Internet of things (IOT) is believed to have important effects on the social production and lifestyle of people and is becoming an important force in promoting social change [1]. IOT technology also makes traditional accounting confusing; thus, accounting theory should be immediately reexamined. This technology also exerts a profound effect on the organization and operation of enterprises, whereas the traditional organization and management model hardly satisfy the developing needs of information technology [2]. For the accounting task in enterprise management, a natural combination of accounting work and information technology should be realized. In the IOT technology environment, the intangible assets of an enterprise are embedded with the help of radio frequency identification (RFID) technology and electronic tags. RFID technology can grasp and manage the details of the circulation of goods in a timely manner, obtain the information of the circulation process of goods, strengthen the supply management of goods, and save the operation cost of enterprises [3]. Electronic tags record and store a huge amount of information regarding tangible assets. The development of IOT in China, however, remains immature, and the system is still imperfect. This study introduces IOT, an accounting platform, a combination of RFID and accounting platform, and the establishment of an intelligent 3D dynamic accounting information platform based on IOT technology.

\section{STATE OF THE ART}

\section{A. IOT}

A large number of items are transmitted in real time through RFID technology, bar codes, and other information-sensing equipment. Data information systems are completed, and the intelligent identification and management of the Internet are realized. The technology system of IOT includes three levels, namely, the perception, network, and application layers [4].

The perception layer is mainly used to collect physical events and data in the physical world, including physical quantity, identification, location information, audio, and video data.

The network layer is the brain and nerve center of IOT, and its main function is to perform information transmission and processing.

The application layer provides the "social division of labor" of IOT. The combination of the application layer and the individual needs of industries can achieve a wide range of intelligence.

\section{B. Accounting Platform}

Modern information technology platforms based on IOT apply computer technology, network communication, and other modern information technology to realize the acquisition, transmission, and processing of intelligent accounting information [5]. Establishing a highly intelligent, real-time, personalized, and dynamic accounting information management system is the core of this system. To improve the accounting information system, the accounting platform enhances the management of enterprises, optimizes the mode of production, and promotes the development of enterprises and the progress of the entire society.

\section{IOT and Accounting Platform}

Accounting is an attribute of social science. The external social environment determines the generation, development, and reform of accounting, as well as introduces accounting ideas, methods, and theories, among others. IOT has far-reaching effects on external and internal accounting environments.

In essence, IOT is the inevitable outcome of development of modern information technology. The develop- 
ment of IOT technology will profoundly change human production and lifestyle. Every wave of science and technology will transform organizational structures and management styles. With the rapid development of information technology, the industrial structure of the world has changed from a material economy to a knowledgebased economy.

\section{METHODOLOGY}

RFID is a non-contact automatic identification technology that provides automatic identification of target objects and access to relevant data through radio frequency signals. RFID is characterized by the use of radio waves to transmit identification information without space constraints. Its most significant advantage is enabling noncontact automatic identification of distant targets moving at high speeds [6].

A complete RFID system generally consists of four parts, namely, a tag, a reader, an antenna, and a management system (Figure 1).

Label: The label consists of a coupling element and a chip. The tag contains a built-in antenna for communicating between the radio frequency antenna and the antenna.

Reader: The reader is a device for reading or rewriting electronic tag information. This device can be designed as a single whole, or it can be embedded into other systems as part of the entire structure. The reader is connected with a computer data management system to complete the identification, operation, and control of electronic tags.

Antenna: The antenna can release radio signals to excite the RFID tag. This part is generally integrated into the reader, which can either be a handheld device or large fixed equipment.

Operation principle: The reader transmits a particular frequency of the radio frequency signal through the transmitting antenna. When the electronic tag enters the working area of the transmitting antenna, the induction current is generated. The tag then obtains the energy to be activated and automatically encodes the information on the card. The receiving antenna of the system receives the carrier signal transmitted from the radio frequency card, and the carrier signal is transmitted to the reader through the antenna regulator. Mediation and decoding of the received signal are conducted through the host computer and into the background management system for the corresponding processing.

\section{RESUlt ANALYSIS AND DisCUSSION}

\section{A. General Design of the Accounting Information Platform}

Accounting and daily management constitute the main contents of the enterprise accounting information system. Accounting covers the following parts: data acquisition, cost accounting, and accounting document generation and report output.

Data acquisition: In IOT technology, for the raw materials purchased by an enterprise, an embedded RFID electronic tag stores the identity information of the manufacturer, which covers various important properties of objects.
Cost accounting: The selection of standard cost accounting becomes viable for enterprises in IOT technology $[7,8]$.

Accounting document generation and report output: Under IOT technology, the original documents or the documents pertaining to production and operation are replaced with the electronic tags of RFID. The electronic tags can automatically generate the accounting documents in real time, thereby eliminating the need for manual entry and significantly reducing the workload of the accountant [9].

In IOT technology, the daily management of the accounting information system includes personnel and process management.

Personnel management: RFID technology provides each accounting staff with different permissions. Each access authorization is embedded into an electronic chip carried by each of the accounting staff. With the help of RFID technology, each electronic identification card con-

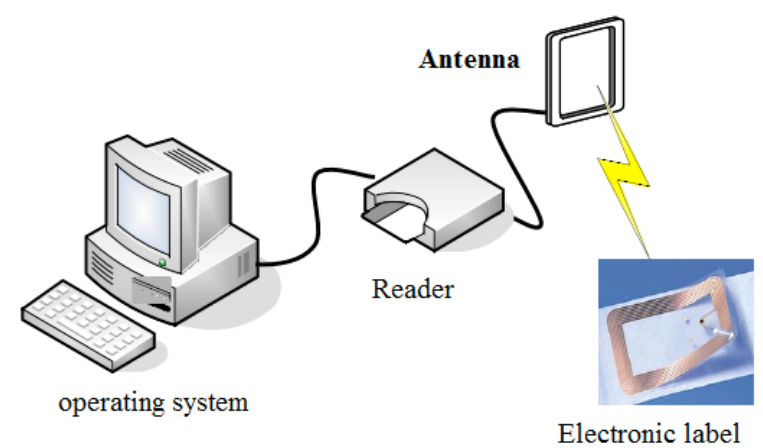

Figure 1. RFID

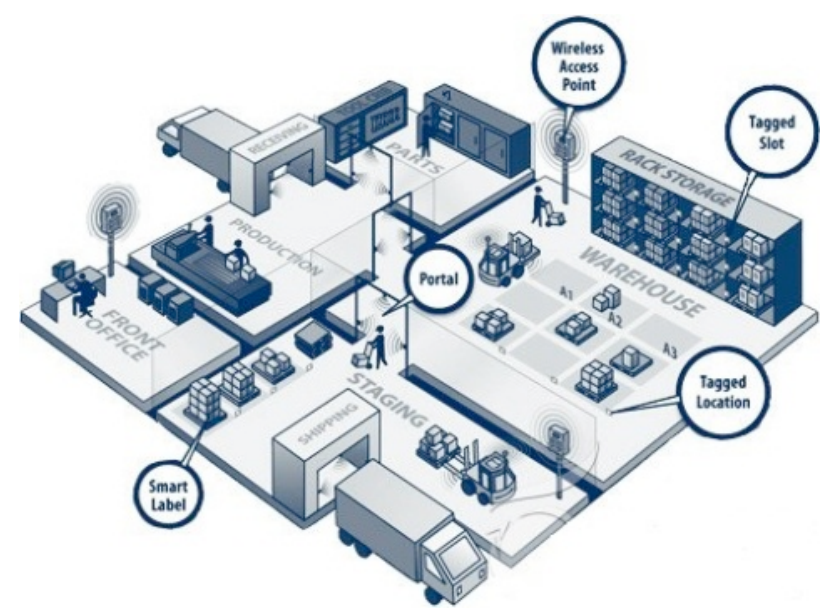

Figure 2. Sketch of data acquisition map

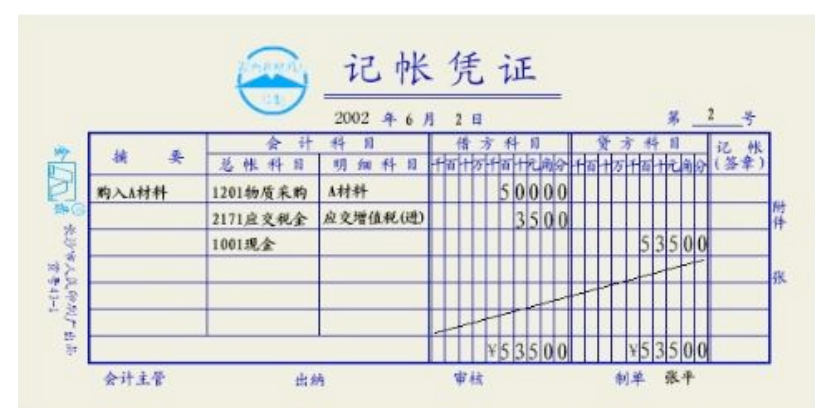

Figure 3. Accounting document generation 


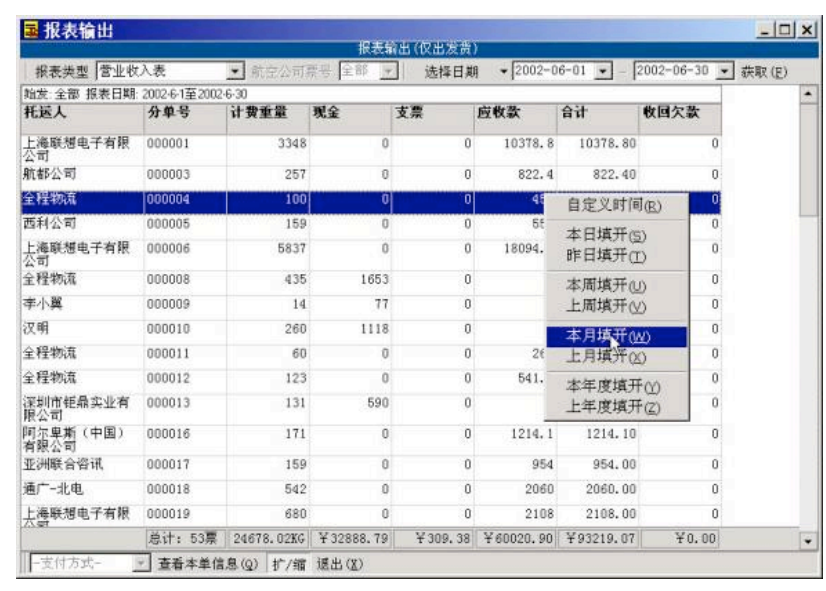

Figure 4. Accounting report output

tains detailed records of all the information of each staff, including his/her identity, authority, tasks, and so on. The chip can also store all job-related data in real time.

Business process management: Real-time information in different stages of RFID technology will be transferred to the corresponding data area in real time. Relevant information on the external market of an enterprise is also updated to the corresponding database through the data communication network. Under IOT, enterprise management can realize omni-directional and $3 \mathrm{D}$ analyses and decisions through data warehousing, with the aid of data mining technology.

\section{B. Subsystem Design}

The hardware part of the fixed asset management system under IOT technology consists of four parts, namely, the reader, the RFID tag, the wireless link, and the data center [10].

The structure design of the software system for fixed asset management is also divided into four modules, namely, the data receiving and sending, data conversion, data storage and processing, and application layer modules. These four modules are related to one another.

\section{CONCLUSION}

With the continuous development of society, accounting information has also underwent important changes. IOT, as a revolution in information technology, will profoundly change the accounting environment and promote the accounting information working process. IOT technology and the intelligent 3D dynamic accounting information platform are related to people, things, information and software systems, and other elements. This study introduces the characteristics of IOT technology and accounting information and integrates radio frequency technology into the accounting information platform. Through
RFID technology, the overall and subsystem designs of an intelligent stereodynamic accounting information platform are completed. The overall design of the intelligent 3D dynamic accounting information platform covers data collection, cost accounting, and accounting document generation and report output. IOT optimizes enterprise management, expands the broad field of vision, and establishes a real-time, transparent, and efficient accounting information system to promote vitality.

\section{REFERENCES}

[1] Jung, Hun. "Study on the MQTT protocol design for the application of the real-time HVAC System", International Journal of Internet, Broadcasting and Communication, 2016, vol 8, no. 1, pp. 65-72.

[2] Rho, Seungmin, Wenny Rahayu, and Geyong Min. "Guest Editorial: Challenges of Embedded Systems as They Evolve into M2M, Internet of Things", ACM Transactions on Embedded Computing Systems (TECS), 2016, vol. 15, no. 2, pp. 34. http://dx.doi.org/10. $1145 / 2886417$

[3] Atanasov, Ivaylo, et al. "An Approach to Data Annotation for Internet of Things", International Journal of Information Technology and Web Engineering (IJITWE), 2015, vol. 10, no. 4, pp. 1-19. http://dx.doi.org/10.4018/IJTTWE.2015100101

[4] Garcia-Carrillo, Dan, and Rafael Marin-Lopez. "Lightweight CoAP-Based Bootstrapping Service for the Internet of Things", Sensors, 2016, vol. 16, no. 3, pp. 358. http://dx.doi.org/10.3390/ $\underline{\mathrm{s} 16030358}$

[5] Rozas Liras, Julio A., et al. "TRUFA: A user-friendly web server for de novo RNA-seq analysis using cluster computing", Evolutionary Bioinformatics, 2015, vol. 11, pp. 97-104.

[6] Leon, Miguel, and Ning Xiong. "Adapting Differential Evolution Algorithms for Continuous Optimization Via Greedy Adjustment Of Control Parameters", Journal of Artificial Intelligence and Soft Computing Research, 2016, vol. 6, no. 2, pp. 103-118. http://dx.doi.org/10.1515/jaiscr-2016-0009

[7] Castillo-Ramírez, S., et al. "Trans-Atlantic exchanges have shaped the population structure of the Lyme disease agent Borrelia burgdorferi sensu stricto", Scientific Reports, 2016, vol. 6, pp. 22794. http://dx.doi.org/10.1038/srep22794

[8] Zhao, Haitao, et al. "E-MAC: An evolutionary solution for collision avoidance in wireless ad hoc networks", Journal of Network and Computer Applications, 2016, vol. 65, pp. 1-11. http://dx.doi.org/10.1016/j.jnca.2016.02.010

[9] Plotkin, Katherine EisenAudrey Barker. "Forty years of forest measurements support steadily increasing aboveground biomass in a maturing, Quercus-dominant northeastern forest", The Journal of the Torrey Botanical Society, 2015, vol. 142, no. 2, pp. 97-112. http://dx.doi.org/10.3159/TORREY-D-14-00027.1

[10] Pennisi, Elizabeth. "Making a game of science", Science, 2016, vol. 351, pp. 1106-1106. http://dx.doi.org/10.1126/science.351. $\underline{6277.1106}$

\section{AUTHOR}

Feng Qiu is with the Chongqing College of Electronic Engineering, Chongqing, China (63117131@qq.com).

Submitted, January, 17, 2016. Published as resubmitted by the author on May, 16, 2009. 